\title{
THE ESSENCE OF ENVIRONMENTAL BIOLOGY
}

\author{
Matthew N. O. Sadiku1* ${ }^{*}$, Tolulope J. Ashaolu², Abayomi Ajayi-Majebi' ${ }^{3}$, and Sarhan M. Musa1
}

${ }^{1}$ Roy G. Perry College of Engineering, Prairie View A\&M University, Prairie View, TX, USA

${ }^{2}$ College of Food Science, Southwest University, Tiansheng Road Beibei District, Chongqing, 400715, P.R. China

${ }^{3}$ Department of Manufacturing Engineering, Central State University, P.O. Box 1004, Wilberforce, OH, USA

E-mail: sadiku@ieee.org; ashaolut@gmail.com; ajayi-majebi@centralstate.edu; smmusa @pvamu.edu

*Corresponding author details: Professor Matthew N. O. Sadiku, sadiku@ieee.org

\begin{abstract}
Environmental biology studies the ways organisms, species, and communities influence, and is impacted by natural and human-altered ecosystems. It explores the interconnections among biology, ecology, evolution, environmental science, and conservation. It is a thriving field that is in dear need of enthusiastic, passionate, and well-trained professionals. Environmental biologists focus on the biology of ecosystems and environmental processes, causes and consequences of environmental change, and how environmental change impacts life on earth. This paper provides an introduction into environmental biology.
\end{abstract}

Keywords: environment; environmental biology; ecology

\section{INTRODUCTION}

In a modern society, it is easy to forget that our society depends largely on the environmental processes that govern our world. The basis of our economy depends on the soils that sustain our agriculture, the rivers that provide our water, the minerals that provide the raw materials for the goods we consume, and the plants and animals that serve as our food [1]. Human inventiveness has introduced chemicals and materials into the environment. The natural environment is different from the built environment, which comprises the areas that are influenced by humans.

Environmental biology is a discipline in science at the intersection of environmental science, ecology, evolution, conservation, and global change. Environmental biology examines the ways organisms, species, and communities influence, and is impacted by, natural and human-altered ecosystems. It covers all the fundamental concepts of the life sciences, including genetics, speciation, evolution, growth and differentiation, metabolism and bio-energetics, ecology, and behavior. It addresses many relevant issues that affect us on a daily basis, such as energy conservation, air pollution, sustainable development, environmental toxins, etc. Figure 1 shows some aspect of environmental biology [2].

\section{ENVIRONMENTAL BIOLOGY AND ECOLOGY}

"Environmental biology" is often considered synonymous for "ecology." These two terms depict the same thing and they appear like the two sides of the same coin.

Although both fields study ecosystems, environmental biology focusses more on the "biological organisms of environment." Ecology is literally the study of "houses" or more broadly, "environments." It is the study of how living organisms interact with their environment. Its main focus has been on various types of ecosystems - terrestrial, fresh water, marine and on how human activity has influenced these ecosystems. There are several types of ecology, such as ecosystem ecology, restoration ecology, physiological ecology, landscape ecology, animal ecology, practical ecology, and plant ecology. Ecologists essentially seek to explain interactions, interrelationships, behaviors, and adaptations of organisms. It is important to note that ecology is not synonymous with environment, environmentalism, natural history, or environmental science. Ecological literacy involves a basic understanding of how the world works and understand the connections between living and nonliving things. Figure 2 shows what ecology is all about [3].

\section{ENVIRONMENTAL BIOLOGISTS}

An environmental biologist studies the biology of specific organisms and their interactions with the environment. Environmental biologists are mainly responsible for monitoring environmental conditions and collecting water and soil samples from the field. Some monitor pollution levels to ensure compliance with state and federal laws. They assist companies to comply with regulations and conduct environmental impact assessments for their development projects. Environmental biologists often need to document their findings [4]. Becoming an environmental biologist has never been more exciting. Figure 3 shows a typical environmental biologist at work [5].

Environmental biologists are needed in different areas such as food and agriculture, environmental education, natural resources sector, environmental consulting, non-governmental environmental organizations, environmental $R \& D$, conservation and environmental protection, government agencies, biotechnology, and renewable energy. They work for their local environmental agencies, municipalities, the National Park Service, Forestry Service, Department of Commerce, the Environmental Protection Agency, the National Oceanic and Atmospheric Administration, National Institutes of Health, and other agencies. They also serve as field technicians, laboratory technicians, international relations, researchers for private or government laboratories, etc. [6]. 
A training on environmental biology could focuses on: (i) the biology of ecosystems and environmental processes, (ii) the causes and consequences of environmental change, and (iii) how environmental change impacts life on earth. It will provide the following skills [7]:

- Contemporary field and lab methods in ecology, evolution, and conservation biology

- Contemporary field and lab methods in environmental science for soil, water, air, and climate assessments

- Assessment of how toxic compounds impact life on earth, from individuals to species to communities

- Climate change impact assessments

- Climate change modelling with a focus on biodiversity impacts

- Environmental impact assessments and audits

- Design of applied environmental and ecological experiments

- Quantitative methods for collecting and interpreting ecological and environmental data

- Application of ecological research for environmental policy- and decision-making

- Earth imaging, including Geographic Information Systems (GIS) and Remote Sensing (RS), for environmental problem solving and conservation

- Development of strong communication skills, including critical reading and writing

While responsibilities may vary significantly from one job to another, environmental biologists are responsible for the following [7].

- Plan and execute complex analytical biological testing following field and laboratory standard operating procedures

- Manage biological and project timelines by using testing expertise, advanced chemical and biological knowledge, and statistical tools

- Be prepared to present results to various stakeholders, both collegial and business

- Build professional international relationships to support the advancement of knowledge

- Understand, apply, and communicate scientific concepts and results.

- Ensure that equipment is maintained for quality control and assurance of lab results, and for safety purposes

- Document and analyze all lab and field results, paying particular attention to calculations and observations in lab documentation

- Review peers' data analyses for accuracy and scientific integrity

- Alert the project leader of unusual results and samplings and of any difficulties or problems encountered during the scope of work

\section{GLOBAL ENVIRONMENTAL BIOLOGY}

The field of Environmental biology is broad and global. Although environmental impact varies significantly between nations, global inequalities in resource consumption and purchasing power mark the clearest dividing line between the haves and the have-nots. Environmental biology covers topics from molecules to ecosystems to regional landscapes. It can encompass areas such botany, zoology, biochemistry, ecology, physiology, animal behavior, geology, mathematics, and conservation. Education and training on environmental biology will vary depending on the location and expertise of the faculty. about 60 times more resources than someone in the developing world. We now consider how environmental biology is handled in some countries.

\section{United States:}

United States and other developed nations tend to have the most problem with the degradation of ecosystems and harming the world's poorest people. Environmental justice is a social movement that attempts to identify and remedy environmental injustices: when environmental benefits and burdens are unfairly distributed. The country's aging infrastructure will also need be replaced. To help meet the demand for specialized expertise in environmental biology, several university in the US are offering courses and degrees in the area.

\section{United Kingdom:}

The world's population of has changed over time and the population of the UK is no exception. The carrying capacity of the UK for people is difficult to determine and depends on whether one means the carrying capacity with respect to sustainable food production or renewable energy resources. Some have argued that the quality of life would be much better in the UK if there were only half or a third the number of people there are today. In that case, there would be less pollution, more room for wildlife, and less traffic jams [8].

\section{Australia:}

The average yield of Australia's major grain (wheat) rose at its fastest rate ever during the last decade. The environmental biology behind this advance was predominantly ecological and nutritional. Applying nitrogen fertilizers became less risky. This allowed farmers to use much more fertilizers and thereby produced more. In spite of Australia's reputation for being drought prone, its crop yields have not hitherto been typically limited by water - poor health and poor nutrition have been more influential [9].

\section{CONCLUSION}

Environmental issues are now part of every career path and employment area. These issues are immensely complex, involving aspects of history, philosophy, behavior, science, economics, social justice, and politics. Environmental biology is the branch of biology which focuses on how organisms interact with the environment, and how they adapt to changing environments.

The job outlook for environmental biologiests is growing faster than the average for all occupations. The National Association of Environmental Professionals (NAEP) is a multidisciplinary association for all types of environmental professionals.

Many schools now offer courses on environmental biology, some online. Introducing education and awareness of environmental biology into academic curriculum helps students grasp the scientific foundation of environmental issues so they can better understand the world around them and their impact on it. More information about environmental biology can be found in the books in $[8,10$ 25] and the following related journal:

- Journal of Environmental Biology

- Expert Opinion on Environmental Biology

- $\quad$ The Open Journal of Environmental Biology

- $\quad$ Advances in Environmental Biology 


\section{REFERENCES}

[1] "Course Syllabus: BIOL 2650: Environmental Biology,"https://www.csustan.edu/sites/default/fi les/groups/Department\%20of\%20Biological\%20S ciences/documents/syllabi/spring_2013/biol/biol 2650.001.pdf

[2] NSF, "Long term research in environmental biology,"https://www.nsf.gov/news/newsmedia/E NV-discoveries/LTREB-discovery-series.jsp

[3] https://www.pinterest.com/pin/2001991459145 62663/

[4] "Career options after environmental biology,"https://utsc.utoronto.ca/aacc/careeroptions-after-environmental-biology

[5] "A career in the wild world of biology," https://www.aibs.org/careers/?gclid=EAIaIQobCh MI8casivDw7AIVw5JbCh0eYghNEAAYASAAEgLDC PD_BwE

[6] "Environmental biology degree," https://www.environmentalscience.org/degree/e nvironmental-biology

[7] "What is an environmental biologist?" https://www.environmentalscience.org/career/en vironmental-

biologist\#: :text=Environmental\%20biologists $\% 2$ 0are\%20mainly\%20responsible,soil\%20samples\% 20 from $\% 20$ the $\% 20$ field.

[8] M. Reiss and J. Chapman, Environmental Biology. Cambridge University Press, 2nd edition, chapter 1, 2000.

[9] J. B. Passioura, "Review: Environmental biology and crop improvement," Functional Plant Biology, vol. 29, no. 5, May 2002, pp. 537-546.

[10] P.S. Verma and V. K. Agarwal, Environmental Biology: Principles of Ecology. New Delhi, India: Publisher S. Chand \& Co, 2000.

[11] M. R. Fisher, Environmental Biology. Open Oregon Educational Resources, 2018.

[12] B. Bhatia, G. S. Chhina, and B. Singh, Selected Topics in Environmental Biology. Pergamon, January 1977.

[13] M. Gupta, Fundamentals of Environmental Biology. I K International Publishing House, 2018.

[14] D. A. Vaccari, P. F. Strom, and J. E. Alleman, Environmental Biology for Engineers and Scientists. Wiley-Interscience, 2005.

[15] F. Deeba, Ecology and Environmental Biology. Centrum Press, 2017.

[16] I. H. Zaheed, A Text Book on Environmental Biology. New Delhi, India: Discovery Publishing House, 2013.
[17] L. M. Lynn, Environmental Biology and Ecology Laboratory Manual. Kendall Hunt Publishing; 6th edition, 2016.

[18] H. R. Singh, Environmental Biology. S. Chand Publishing, 2nd edition, 2004.

[19] G. Tripathi, Modern Trends in Environmental Biology. CBS Publishers \& Distributors, 2002.

[20] J. Ramsay and J. Schroer, Environmental Biology. Kendall Hunt Publishing Co., 2020.

[21] S. Z. Ali, Environmental Biology. Akhand Publishing House, 2019.

[22] P. S. Nobel, Environmental Biology of Agaves and Cacti. Cambridge University Press, 2003.

[23] A. J. Bailer, Statistics for Environmental Biology and Toxicology. Boca Raton, FL: CRC Press, 2020.

[24] P. D. Sharma, Environmental Biology and Toxicology. Rastogi Publication, 2005.

\section{AUTHORS}

Matthew N.O. Sadiku is a professor emeritus in the Department of Electrical and Computer Engineering at Prairie View A\&M University, Prairie View, Texas. He is the author of several books and papers. His areas of research interests include computational electromagnetics and computer networks. He is a fellow of IEEE.

Tolulope J. Ashaolu works at Southwest University. He is the author of several papers and two books. His research interests include functional foods and food microbiology.

Abayomi Ajayi-Majebi is a professor in the Department of Manufacturing Engineering at Central State University in Wilberforce, Ohio. In 2015 he was honored by the White House as a Champion of Change for his significant contributions to the engineering education of minority students. He is a senior member of both the Society of Manufacturing Engineers and the American Society for Quality.

Sarhan M. Musa is a professor in the Department of Electrical and Computer Engineering at Prairie View A\&M University, Prairie View, Texas. He has been the director of Prairie View Networking Academy, Texas, since 2004. He is an LTD Sprint and Boeing Welliver Fellow. His areas of research interests include computational.

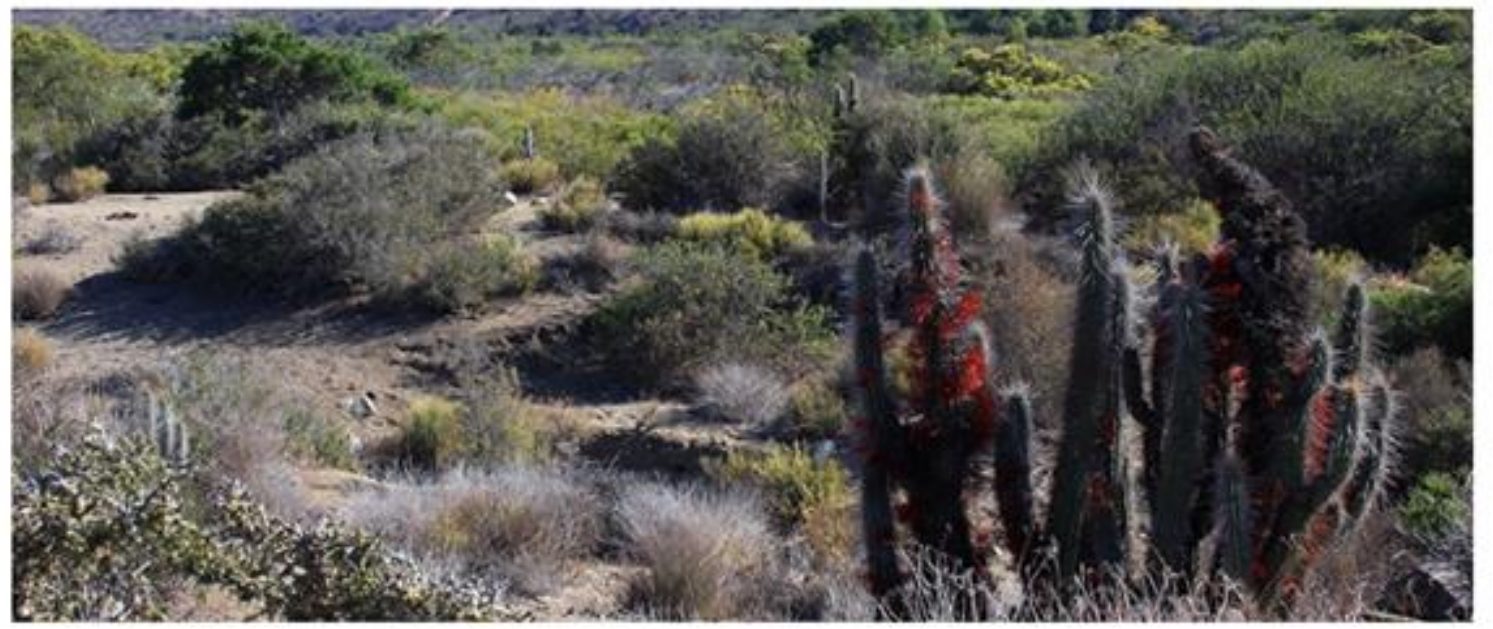

FIGURE 1: CONSERVATION OF NATURAL HABITATS AND SPECIES [2] 


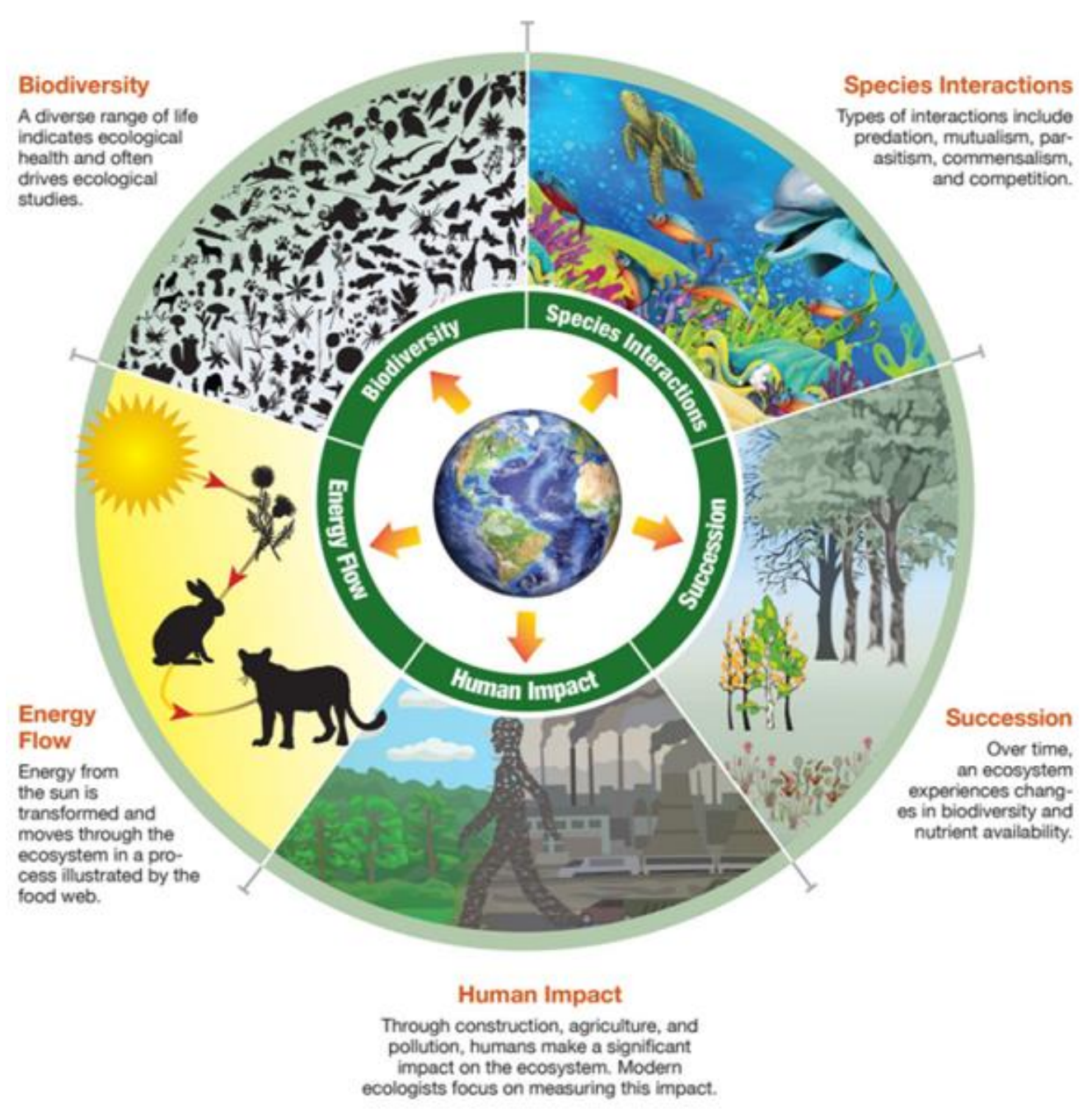

FIGURE 2: THE STUDY OF THE PLACE WE LIVE [3].

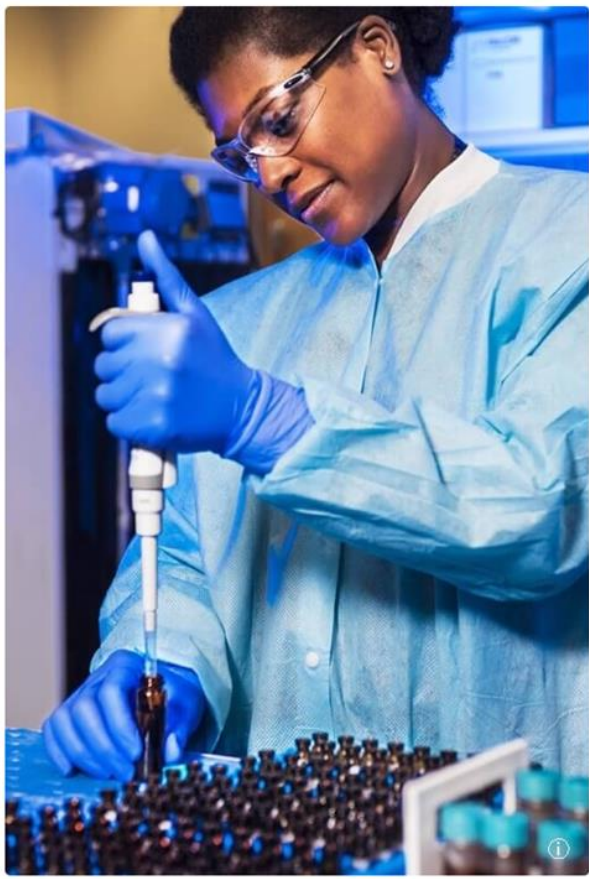

FIGURE 3: AN ENVIRONMENTAL BIOLOGIST AT WORK [5]. 